\title{
$75 \mathrm{mg}$ und $100 \mathrm{mg}$ Hartkapseln
}

\section{Neue Packungsgröße}

\section{Trevilor ${ }^{\circledR}$ retard}

yeth Pharma GmbH erweitert das Spektrum der Packungsgrößen von Trevilor ${ }^{\circledR}$ retard 75 $\frac{\bar{\sigma}}{\bar{\Phi}}$ mg und $100 \mathrm{mg}$ Hartkapseln. Das Antidepressivum Trevilor $^{\circledR}$ (Wirkstoff: Venlafaxinhydrochlorid), das vor kurzem eine Indikationserweiterung erhielt und jetzt auch zur Therapie der Panikstörung mit oder ohne Agoraphobie zugelassen ist, ist ab sofort? auch in Packungsgrößen mit 14 St. erhältlich. 